05

\title{
Влияние малых добавок углеродных нанотрубок на механические свойства эпоксидных полимеров при статических и динамических нагрузках
}

\author{
(C) А.Е. Тарасов, ${ }^{1}$ Э.Р. Бадамшина, ${ }^{1,2}$ Д.В. Анохин, ${ }^{1,3}$ С.В. Разоренов, ${ }^{1,2,{ }^{\top}}$ Г.С. Вакорина ${ }^{1}$ \\ ${ }^{1}$ Институт проблем химической физики РАН, \\ 142432 Черноголовка, Московская обл., Россия \\ ${ }^{2}$ Московский государственный университет им. М.В. Ломоносова, \\ 119991 Москва, Россия \\ ${ }^{3}$ Московский фризико-технический институт (государственный университет), \\ 141700 Долгопрудный, Московская обл., Россия \\ ฯ e-mail: razsv@ficp.ac.ru
}

(Поступило в Редакцию 26 мая 2017 г.)

\begin{abstract}
Представлены результаты измерений механических характеристик отвержденных эпоксидных композитов, содержащих малые и сверхмалые добавки одностенных углеродных нанотрубок в пределах от 0 до 0.133 wt.\% при статических и динамических нагрузках. Статические измерения прочностных характеристик проведены в стандартных условиях испытаний. Измерения динамического предела упругости и откольной прочности выполнялись при ударно-волновом нагружении образцов при скорости деформирования перед разрушением $(0.8-1.5) \cdot 10^{5} \mathrm{~s}^{-1}$ с использованием взрывных устройств путем регистрации и последующего анализа эволюции полных волновых профилей. Показано, что присутствующие в структуре композитов после отверждения агломераты нанотрубок приводят к существенному разбросу измеренных прочностных параметров как в статическом, так и в динамическом режимах испытаний. Однако влияния добавок углеродных нанотрубок в изученном интервале концентраций на сами физико-механические характеристики параметров при обоих видах нагрузки не обнаружено.
\end{abstract}

DOI: 10.21883/JTF.2018.01.45478.2354

\section{Введение}

На примере полиуретановых сшитых эластомеров и линейных блоксополимеров [1] было убедительно доказано, что введение одностенных углеродных нанотрубок $($ ОСУНТ) в концентрациях от 0.001 до $0.02 \mathrm{wt} \%$ существенным образом влияет на структуру этих полимеров и физико-механические свойства образующихся нанокомпозитов. Зависимость физико-механических параметров от концентрации ОСУНТ не линейная, а имеет вид кривой с максимумом в области $0.002 \mathrm{wt} . \%$ ОСУНТ. Большой научный интерес и огромное практическое значение имеют исследования влияния таких сверхмалых добавок углеродных нанотрубок (УНТ) на структуру и свойства эпоксидных полимеров, широко используемых в качестве связующих полимерных композиционных материалов (ПКМ) различного назначения, главным образом конструкционных ПКМ. Побудительной причиной исследования влияния именно сверхмалых добавок наномодификаторов на свойства полимеров является то немаловажное обстоятельство, что ни в настоящее время, ни в ближайшем обозримом будущем полимерные композиты, содержащие УНТ в концентрациях от десятых долей процента до нескольких процентов $(>1-10 \mathrm{~kg} / \mathrm{t})$ вряд ли смогут найти широкое применение, так как объемы производства УНТ несоизмеримы с объемами производства полимеров, а цены на УНТ чрезвычайно высоки. Кроме того, вязкость дисперсий УНТ при увеличении их концентрации до 1 wt.\% становится очень высокой, что существенно затрудняет использование таких связующих для получения ПКМ. Композиты с содержанием УНТ менее 0.01 wt.\% $(<100 \mathrm{~g} / \mathrm{t})$ могут оказаться вполне доступными как с точки зрения технологичности, так и по стоимости, поэтому исследования их свойств в этом интервале концентраций является перспективными не только в плане лучшего понимания природы взаимодействий в системе полимерная матрица/нанонаполнитель, но и для широкого практического применения. Следует отметить, что, несмотря на огромное количество публикаций, посвященных модифицированию эпоксидных смол УНТ (см., например, обзоры [2-4]), практически нет работ, где исследуется влияние сверхмалых добавок наноматериалов на свойства композитов на их основе.

В настоящей работе проведены исследования прочностных свойств отвержденной эпоксидной композиции с добавлением углеродных нанотрубок в малой и сверхмалых концентрациях при статических и динамических нагрузках. Статические измерения проводили в стандартных условиях испытаний на растяжение, динамические нагрузки реализованы в ударно-волновых экспериментах с использованием специальных взрывных устройств. 


\section{1. Исследованные материалы и методы экспериментов}

\section{1. Методы приготовления образцов}

Исследуемые образцы представляли собой композиты на основе эпоксидиановой смолы ЭД-20 (ГОСТ 10587-84), использованной без ее предварительной очистки, с добавлением ОСУНТ в концентрации от 0 до 0.133 wt.\%. Эпоксидное число ЭД-20, определенное методом ${ }^{1} H$ ЯМР-спектроскопии [5], составляет 23.6. В качестве отвердителя использовали технический 4.4-диаминодифенилметан (ДАДФМ) без предварительной очистки. Массовая доля амина на основное вещество - 99\%, температура кристаллизации $87.5^{\circ} \mathrm{C}$, аминный эквивалент - $53.7 \mathrm{~g} / \mathrm{g}$-eq. Отверждение образцов осуществляли при постоянном соотношении ЭД-20/ДАДФМ, равном 100/22.09. ОСУНТ получены дуговым методом на катализаторе $\mathrm{Ni} / \mathrm{Y}$ [6] и очищены окислением в газовой фазе до 90\%-ного содержания. Средние диаметр и длина нанотрубок - 1.4-1.6 nm и $\sim 1.0 \mu \mathrm{m}$ соответственно [7]. После очистки нанотрубки находятся в сильно агломерированном состоянии вследствие большой поверхностной энергии, присущей наночастицам. Удельная поверхность порошка нанотрубок, измеренная по адсорбции азота, составила $\sim 400 \mathrm{~m}^{2} / \mathrm{g}$.

С целью дезагрегации связок нанотрубок перед введением в эпоксидную смолу они подвергались ультразвуковой обработке в ацетоне в течение $1 \mathrm{~h}$ периодами по $15 \mathrm{~min}$ обработки и $15 \mathrm{~min}$ остывания (ультразвуковой диспергатор „IL-10 0.63“). Затем к дисперсии ОСУНТ в ацетоне добавляли расчетное количество отвердителя ДАДФМ, полученную смесь дополнительно подвергали ультразвуковой обработке в течение $1 \mathrm{~h}$. Ацетон удаляли на роторном испарителе до постоянного веса отвердителя с нанотрубками.

В работе использовали два варианта приготовления композита. По первому из них в реактор, снабженный механической мешалкой и рубашкой термостатирования, сначала добавляли эпоксидную смолу, которую выдерживали при $90^{\circ} \mathrm{C}$ при постоянном перемешивании и вакуумировании в течение $30 \mathrm{~min}$. Затем в смолу добавляли расчетное количество ДАДФМ или ДАДФМ с нанотрубками, реакционную смесь снова перемешивали до полного растворения ДАДФМ и термостатировали $\left(90^{\circ} \mathrm{C}\right)$ при вакуумировании в течение $5 \mathrm{~min}$ до остаточного вакуума 50-100 Ра. После чего готовую реакционную массу разливали по предварительно разогретым до $100^{\circ} \mathrm{C}$ силиконовым формам в виде лопаток, соответствующих ASTM D638-02 Tyре V. Формы помещали в термошкаф, в котором происходило ступенчатое отверждение эпоксидной композиции при $100^{\circ} \mathrm{C}$ в течение $3 \mathrm{~h}$, затем при $160^{\circ} \mathrm{C}$ в течение $2 \mathrm{~h}$, после этого при $180^{\circ} \mathrm{C}$ в течение $2 \mathrm{~h}$ [8].

При втором варианте в реактор добавляли эпоксидную смолу, которую, так же как и в первом варианте, выдерживали при $90^{\circ} \mathrm{C}$ при постоянном перемешивании и вакуумировании в течение $30 \mathrm{~min}$. Затем в смолу добавляли расчетное количество ДАДФМ или ДАДФМ с нанотрубками, реакционную смесь снова перемешивали до полного растворения ДАДФМ и термостатировали $\left(60^{\circ} \mathrm{C}\right)$ при вакуумировании в течение $20 \mathrm{~min}$. Затем реакционную массу охлаждали до $20^{\circ} \mathrm{C}$ и перемешивали при данной температуре еще $15 \mathrm{~min}$. Вязкость композиции при этой температуре была такова, что еще позволяла хорошо перемешать композицию и дезагрегировать агломераты нанотрубок, но должна была препятствовать их повторной агломерации. Далее реакционную смесь нагревали до $90^{\circ} \mathrm{C}$, не прекращая перемешивания, и выдерживали при этой температуре до конверсии реагентов, близкой к точке геля. После этого реакционную смесь разливали по предварительно разогретым до $100^{\circ} \mathrm{C}$ силиконовым формам в виде лопаток, соответствующих ASTM D638 I, и отверждали. Отверждение проводили аналогично первому варианту смешения реагентов.

\section{2. Анализ структуры образцов и методы определения их физико-механических характеристик}

Структуру образцов исследовали методами рентгеновской дифракции в малых углах рассеяния с помощью дифрактометра XeuSS (Xenocs, Франция) с генератором GeniX3D $(\lambda=0.154 \mathrm{~nm})$, формирующим пучок размером $300 \times 300 \mu \mathrm{m}$. Двумерные дифрактограммы регистрировали при помощи детектора Pilatus 300k, установленного на расстоянии $1.3 \mathrm{~m}$ от образца. Модуль волнового вектора $s(s=2 \sin \theta / \lambda$, где $\theta-$ угол Брегга) калибровали, используя три порядка дифракции на порошке бегената серебра. После измерений интенсивность нормировали на толщину образца.

Физико-механические испытания отвержденных эпоксидных полимеров (ОЭП) и композитов на их основе (ОЭК) осуществляли на разрывной машине Zwick Z010 TC-FR010TH при скорости деформирования $1 \mathrm{~mm} / \mathrm{min}$. Динамический механический анализ ОЭП и ОЭК проводили на приборе DMA 242 C (фирмы Netzsch-Gerätebau $\mathrm{GmbH}$, Германия) в режиме трехточечного изгиба $(l=20 \mathrm{~mm})$ при непрерывном сканировании температуры от 20 до $200^{\circ} \mathrm{C}$ со скоростью $2^{\circ} \mathrm{C} / \mathrm{min}$ в атмосфере воздуха. К образцам прикладывалась синусоидальная осциллирующая сила, позволяющая развить амплитуду деформации $30 \mu \mathrm{m}$, при фиксированной частоте $1 \mathrm{~Hz}$. Температуру стеклования образцов определяли по значению ординаты максимума пика в области $\alpha$-релаксации на зависимости тангенса угла потерь от температуры.

Ударно-волновое нагружение образцов из ОЭК с различным содержанием ОСУНТ осуществляли с помощью специальных взрывных устройств [9], в которых алюминиевые пластины-ударники разгонялись плоской ударной волной, которая создавалась в стальном ослабителе толщиной $20 \mathrm{~mm}$ с помощью так называемой 
взрывной линзы. Скорость соударения ударников толщиной 0.2 или $0.39 \mathrm{~mm}$ и образцов в этих экспериментах составляла $660 \pm 30 \mathrm{~m} / \mathrm{s}$. Толщина образцов изменялась от 2.18 до $2.88 \mathrm{~mm}$, концентрация ОСУНТ варьировала в пределах от 0 до $0.133 \%$. Измеренная плотность образцов независимо от содержания ОСУНТ составляла $1.16 \pm 0.005 \mathrm{~g} / \mathrm{cm}^{3}$. Во всех экспериментах проводили непрерывную регистрацию скорости свободной поверхности образца от времени $u_{\mathrm{fs}}(t)$ лазерным допплеровским измерителем скорости VISAR [10], имеющим пространственное разрешение около $100 \mu \mathrm{m}^{2}$ и временное разрешение $\sim 1 \mathrm{~ns}$. Для отражения зондирующего лазерного излучения от тыльной поверхности образца на нее накатывалась алюминиевая фольга толщиной $8 \mu \mathrm{m}$. Точность измерения скорости в данных экспериментах составляла $\pm 3 \mathrm{~m} / \mathrm{s}$ независимо от амплитуды ударной волны. Соотношение толщины ударника и образца подбиралось таким образом, чтобы импульс сжатия при выходе на свободную поверхность образца имел треугольную форму, что позволяет рассчитать прочностные характеристики исследуемых образцов с наименьшей погрешностью [11].

\section{2. Обсуждение результатов}

\section{1. Результаты статических измерений}

В серии экспериментов по исследованию влияния ОСУНТ на свойства ОЭК концентрацию нанотрубок изменяли от 0 до $0.1 \mathrm{wt} . \%$, при этом во всех случаях поддерживалось соотношение ЭД-20/ДАДФМ, равное 100/22.09. Как установлено в работе [8], именно такое соотношение и выбранный режим отверждения обеспечивают образование густосшитых ЭОП с оптимальными свойствами. Результаты физико-механических испытаний образцов ОЭК, полученных по первому варианту (ОЭК-І), при статических нагрузках приведены в табл. 1.

Таблица 1. Зависимости физико-механических параметров $(E-$ модуль Юнга, $\sigma-$ прочность на разрыв, $\varepsilon-$ деформация) ОЭК-І от концентрации ОСУНТ

\begin{tabular}{c|c|c|c}
\hline$C_{\text {SWCNT }} \times 10^{3}, \%$ & $E, \mathrm{GPa}$ & $\sigma, \mathrm{MPa}$ & $\varepsilon, \%$ \\
\hline 0 & $3.26 \pm 0.04$ & $95.4 \pm 0.8$ & $5.17 \pm 0.08$ \\
1 & $3.16 \pm 0.06$ & $96.8 \pm 0.7$ & $5.5 \pm 0.1$ \\
2 & $3.1 \pm 0.1$ & $96.2 \pm 0.9$ & $5.7 \pm 0.2$ \\
3 & $3.28 \pm 0.04$ & $97 \pm 1$ & $5.13 \pm 0.07$ \\
4 & $3.21 \pm 0.02$ & $97 \pm 1$ & $5.23 \pm 0.06$ \\
6 & $3.1 \pm 0.2$ & $96.7 \pm 0.2$ & $5.5 \pm 0.3$ \\
8 & $3.11 \pm 0.09$ & $97 \pm 1$ & $5.4 \pm 0.1$ \\
10 & $3.26 \pm 0.04$ & $96.1 \pm 0.5$ & $5.15 \pm 0.07$ \\
20 & $3.3 \pm 0.1$ & $97 \pm 1$ & $5.1 \pm 0.2$ \\
40 & $3.31 \pm 0.05$ & $97 \pm 1$ & $4.9 \pm 0.2$ \\
60 & $3.33 \pm 0.02$ & $96.1 \pm 0.7$ & $4.98 \pm 0.08$ \\
80 & $3.41 \pm 0.02$ & $98.7 \pm 0.6$ & $4.9 \pm 0.2$ \\
100 & $3.41 \pm 0.06$ & $99 \pm 1$ & $4.85 \pm 0.08$
\end{tabular}
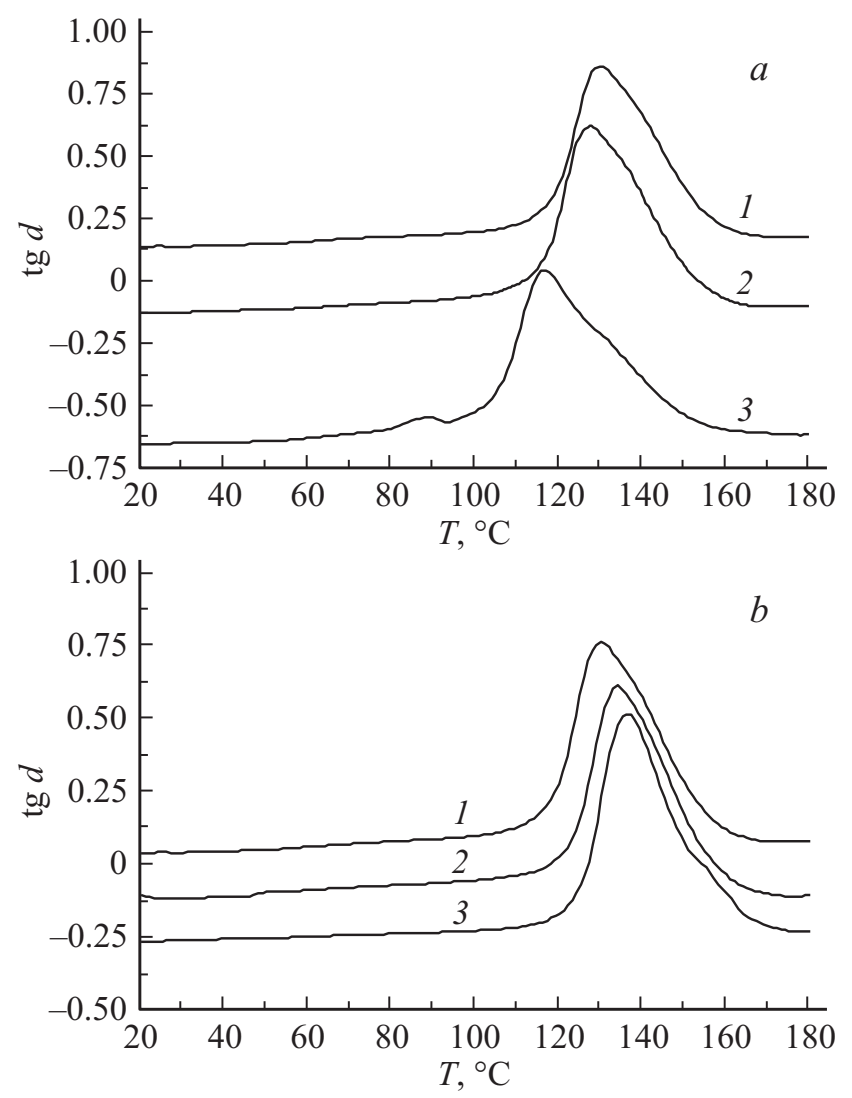

Рис. 1. Зависимость тангенса угла механических потерь от концентрации ОСУНТ. Содержание ОСУНТ: $1-0,2-0.002$, $3-0.08$ mas. $\%$; $a-$ OЭК-I, $b-$ ОЭК-II.

Добавки ОСУНТ оказывают незначительное влияние на физико-механические характеристики отвержденной композиции. Это влияние лишь ненамного превышает ошибки измерения анализируемых величин. Неудовлетворительная воспроизводимость измерений физико-механических параметров ОЭК связана, по всей видимости, с тем, что ОСУНТ образуют агломераты в эпоксидной матрице в процессе отверждения, действующие как концентраторы напряжения при растяжении, с которых начинается разрушение образца, о чем свидетельствуют и результаты электронно-микроскопических исследований. В отсутствие нанотрубок разрушение начинается с дефекта на поверхности образца, в то время как разрушение образцов, содержащих ОСУНТ, - с агломератов нанотрубок, находящихся внутри образца.

Образование агломератов подтверждается и результатами анализа образцов методом ДМА. Наличие нанотрубок приводит к изменению формы пика в области $\alpha$-релаксации на графике зависимости тангенса угла механических потерь от температуры (рис. 1,a) и снижению температуры стеклования с ростом концентрации нанотрубок. Это обусловлено, по всей вероятности, возникновением неоднородных по густоте сшивки участков композита, причем дополнительную сшивку могут обеспечивать нанотрубки, что особенно заметно 
проявляется в случае ОЭК-I, содержащего 0.08 wt.\% ОСУНТ (кривая 3, рис. 1,a).

Для подавления образования крупных агломератов нанотрубок был изменен способ приготовления композита (вариант 2, ОЭК-ІІ). В этом случае наблюдаются более равномерное распределение нанотрубок в матрице по сравнению с ОЭК-І и более однородная структура ОЭК-ІІ. Так, пики в области $\alpha$-релаксации на зависимости тангенса угла потерь от температуры не уширены по сравнению с эталонным образцом, не содержащим нанотрубок, и не имеют ярко выраженного плеча или вторых пиков, кроме того, в этом случае с ростом содержания нанотрубок температура стеклования ОЭК-ІІ практически не меняется.

Тем не менее и при втором способе приготовления композитов полностью дезагригировать связки ОСУНТ до индивидуальных трубок не удается, а существуют они в виде более мелких агломератов по сравнению с агломератами в ОЭК-I, свидетельством чему являются результаты рентгеноструктурного анализа. Из них следует, что, во-первых, во всех образцах ОЭК, включая и приготовленные по второму варианту, отсутствуют упорядоченные структуры, о чем можно судить по отсутствию максимумов на кривых рассеяния рентгеновских лучей в малых углах (рис. 2). Во-вторых, с увеличением содержания ОСУНТ в образцах интенсивность рассеяния возрастает. Подобные флуктуации электронной плотности и рост инварианта рассеяния обычно связаны с формированием в системе нерегулярных неоднородностей. В нашем случае это могут быть нерегулярные неоднородности матрицы вокруг крупных агломератов нанотрубок в ОЭК-І и более мелких — в ОЭК-ІІ.

Наличие даже некрупных агломератов приводит к тому, что абсолютная ошибка измерений физико-механических параметров ОЭК-II практически идентична таковой для ОЭК-І. Изменения физико-механических параметров ОЭК-ІІ с ростом концентрации нанотру-

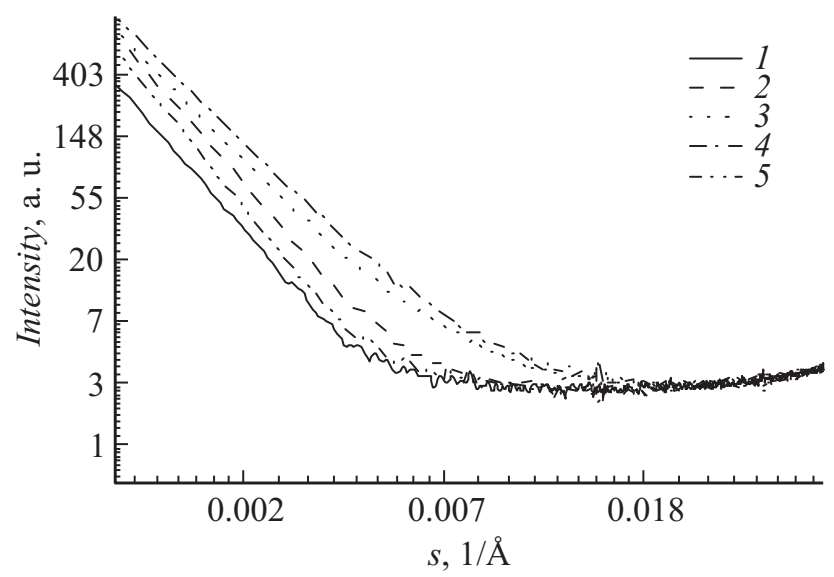

Рис. 2. Кривые рассеяния рентгеновских лучей в малых углах. Содержание ОСУНТ в образцах, полученных по первому варианту: $1-0,2-0.002,3-0.08$ mas.\%; по второму варианту: $4-0.08,5-0.004$ mas. $\%$.
Таблица 2. Зависимости физико-механических параметров $(E-$ модуль Юнга, $\sigma$ - прочность на разрыв, $\varepsilon-$ деформация) ОЭК-ІІ от концентрации ОСУНТ

\begin{tabular}{c|c|c|c}
\hline$C_{\text {SWCNT }} \times 10^{3}, \%$ & $E, \mathrm{GPa}$ & $\sigma, \mathrm{MPa}$ & $\varepsilon, \%$ \\
\hline 0 & $3.07 \pm 0.06$ & $94.8 \pm 0.9$ & $5.2 \pm 0.2$ \\
4 & $3.2 \pm 0.03$ & $96 \pm 2$ & $5.0 \pm 0.1$ \\
6 & $3.1 \pm 0.2$ & $95 \pm 2$ & $5.1 \pm 0.4$ \\
8 & $3.09 \pm 0.09$ & $96 \pm 1$ & $5.3 \pm 0.3$ \\
10 & $3.07 \pm 0.05$ & $96 \pm 1$ & $5.2 \pm 0.2$ \\
20 & $3.1 \pm 0.1$ & $94 \pm 0.7$ & $4.9 \pm 0.6$ \\
40 & $3.0 \pm 0.1$ & $94.6 \pm 0.9$ & $5.2 \pm 0.2$ \\
60 & $2.9 \pm 0.1$ & $93 \pm 1$ & $5.0 \pm 0.4$ \\
80 & $3.04 \pm 0.08$ & $95.6 \pm 0.5$ & $5.2 \pm 0.1$ \\
100 & $3.1 \pm 0.1$ & $94 \pm 2$ & $4.6 \pm 0.6$
\end{tabular}

бок находятся в пределах $2-4 \%$ от соответствующих значений эталонного образца, не содержащего ОСУНТ (табл. 2).

\section{2. Результаты ударно-волновых экспериментов}

Прочностные свойства материалов при динамических воздействиях исследуются в условиях импульсного (ударного) воздействия на вещество, когда длительность нагрузки составляет микросекунды и менее. Измерения основываются на том факте, что структура ударных волн и динамика волновых взаимодействий определяются процессами, связанными с изменением сжимаемости вещества при ударном нагружении вследствие полиморфных или фазовых превращений, разной сжимаемости вещества при упругом и пластическом деформировании материала, при образовании дефектов в материале или его разрушении и т.д. $[9,12]$. Анализ эволюции (формоизменения) импульса сжатия в процессе прохождения последнего по образцу дает необходимую информацию о сопротивлении материала динамическому деформированию и разрушению. Как правило, при таких измерениях в образцах генерируется импульс одномерного сжатия при соударении плоского образца с плоской пластиной-ударником, разогнанной каким-либо способом до больших (от десятков метров до нескольких километров в секунду) скоростей. В процессе нагружения проводится регистрация полного волнового профиля, который включает в себя историю нагружения и разгрузки. В большинстве случаев при исследовании прочностных свойств материалов в ударных волнах регистрируется зависимость скорости свободной тыльной поверхности плоского образца от времени в процессе выхода на нее импульса сжатия - профиль скорости свободной поверхности $u_{\mathrm{fs}}(t)$. Разрушение материала при микросекундных и субмикросекундных длительностях нагрузки характеризуется так называемой откольной прочностью - критическими растягивающими напряжениями, которые генерируются внутри образца 


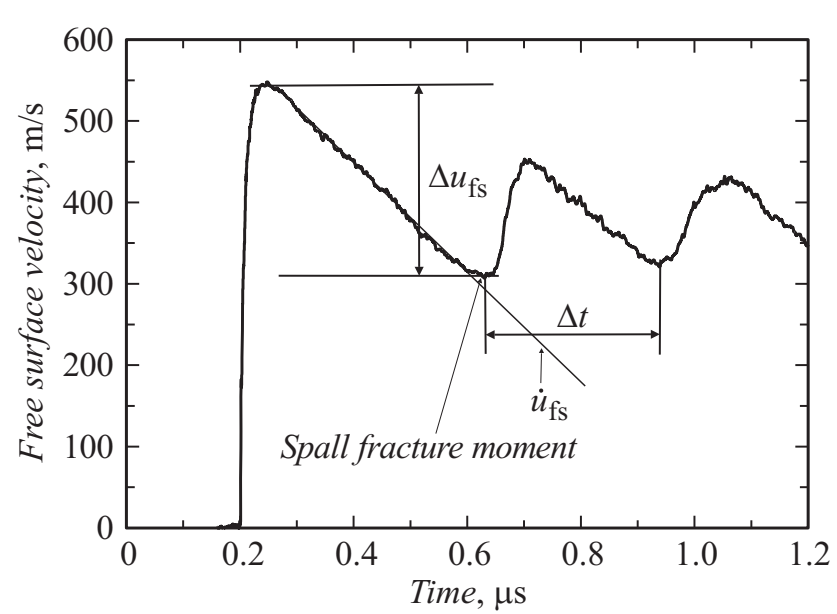

Рис. 3. Профиль скорости свободной поверхности образца ОЭК-І, содержащего $0.001 \%$ ОСУНТ. Толщина образца $2.53 \mathrm{~mm}$.

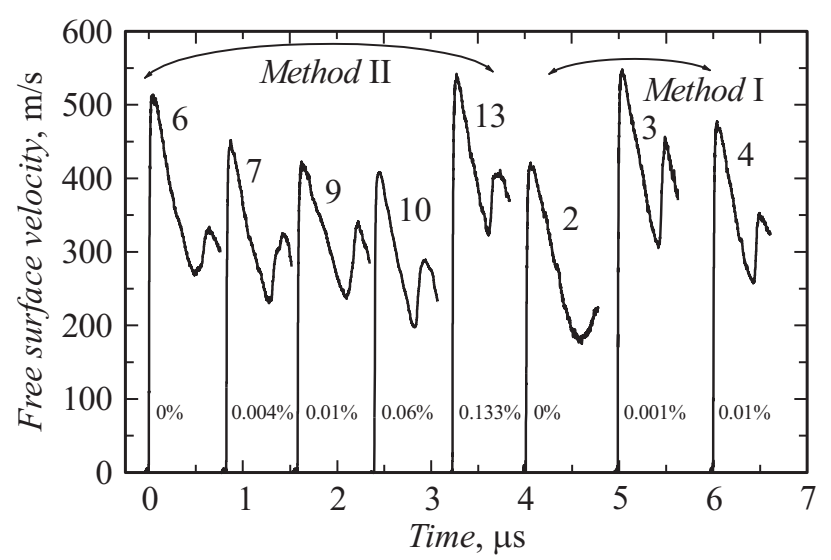

Рис. 4. Профили скорости свободной поверхности образцов ОЭК-І и ОЭК-ІІ с различной концентрацией ОСУНТ. Числами у профилей указаны номера образцов в соответствии с табл. 1 и табл. 2, а также концентрация ОСУНТ в образцах. Профили произвольно смещены по времени.

при отражении импульса сжатия от его тыльной поверхности. В настоящей работе проведены измерения откольной прочности образцов ОЭК в зависимости от концентрации ОСУНТ при интенсивности импульса сжатия от 0.7 до $1 \mathrm{GPa}$ и скоростях деформирования перед разрушением материала в диапазоне $(0.8-1.5) \cdot 10^{5} \mathrm{~s}^{-1}$.

На рис. 3 приведен типичный волновой профиль, полученный в эксперименте с образцом ОЭК-I, содержащем 0.001 wt.\% ОСУНТ. На всех измеренных профилях скорости свободной поверхности образцов с различной концентрацией нанотрубок регистрируется резкий скачок параметров во фронте ударной волны, соответствующий ее выходу на свободную поверхность. При выбранном соотношении толщин ударника и образца больше, чем 1:5, условия нагружения вблизи свободной тыльной поверхности образца соответствуют началу затухания ударной волны под действием нагоняющей ее волны разрежения, и вследствие этого импульс сжатия имеет треугольную форму. Волна разгрузки уменьшает скорость поверхности до минимального значения в момент времени, соответствующий началу откольного разрушения. При взаимодействии волн разрежения с тыльной поверхности образца и тыльной поверхности ударника, направленных в противоположные стороны, внутри образца генерируются растягивающие напряжения, которые при достижении критической для данного образца величины приводят к формированию внутри него трещины и последующему разделению его на части - откольному разрушению [13]. Напряжения внутри материала, при которых происходит откольное разрушение, называются откольной прочностью материала. Критические разрушающие напряжения при отколе пропорциональны спаду скорости от максимума до первого минимума в момент откола $\Delta u_{\mathrm{fs}}$ (рис. 3), который определяется из экспериментальных профилей скорости $u_{\mathrm{fs}}(t)$. Величина откольной прочности $\sigma_{\mathrm{sp}}$ рассчитывается по соотношению [10,13]: $\sigma_{\mathrm{sp}}=\rho_{0} C_{b} \Delta u_{\mathrm{fs}}$, где $\rho_{0}$ - исходная плотность образцов, $C_{b}-$ объемная скорость звука.

При образовании откольной трещины происходит релаксация растягивающих напряжений до нуля, и, как результат, формируется волна сжатия (откольный импульс), выход которой на поверхность образца вызывает второй подъем ее скорости. Затухающие по амплитуде колебания скорости связаны с многократным переотражением откольного импульса в оторвавшейся от образца откольной пластине. На рис. 3 представлены только первые два из них. Анализ волновых профилей позволяет получить также толщину откольной пластины $h_{\mathrm{sp}}$, которая формируется при откольном разрушении. Ее значение рассчитывается из соотношения

Таблица 3. Измеренная продольная скорость звука образцов ОЭК и параметры ударно-волновых экспериментов

\begin{tabular}{c|c|c|c|c|c|c}
\hline $\begin{array}{c}\text { Номер } \\
\text { эксперимента }\end{array}$ & $\begin{array}{c}\text { ОСУНТ, } \\
\%\end{array}$ & $\begin{array}{c}C_{l}, \\
\mathrm{~km} / \mathrm{s}\end{array}$ & $\begin{array}{c}h_{\text {sam }}, \\
\mathrm{mm}\end{array}$ & $\begin{array}{c}h_{\mathrm{imp}}, \\
\mathrm{mm}\end{array}$ & $\begin{array}{c}u_{\mathrm{ss} \max } \\
\mathrm{m} / \mathrm{s}\end{array}$ & $\begin{array}{c}P_{\max }, \\
\mathrm{GPa}\end{array}$ \\
\hline \multicolumn{6}{|c}{ Метод I } \\
\hline 1 & 0 & 2.741 & 2.68 & 0.39 & 634 & 1.17 \\
2 & 0 & 2.741 & 2.88 & 0.21 & 417 & 0.73 \\
3 & 0.001 & 2.716 & 2.53 & 0.21 & 545 & 0.98 \\
4 & 0.01 & 2.777 & 2.55 & 0.21 & 470 & 0.83 \\
5 & 0.1 & 2.719 & 2.52 & 0.21 & 486 & 0.86 \\
\hline \multicolumn{6}{|c}{ Метод II } \\
\hline 6 & 0 & 2.741 & 2.59 & 0.21 & 511 & 0.91 \\
7 & 0.004 & 2.705 & 2.36 & 0.21 & 450 & 0.79 \\
8 & 0.004 & 2.705 & 2.77 & 0.21 & 404 & 0.7 \\
9 & 0.01 & 2.733 & 2.6 & 0.21 & 418 & 0.73 \\
10 & 0.06 & 2.661 & 2.56 & 0.21 & 537 & 0.97 \\
11 & 0.08 & 2.69 & 2.18 & 0.21 & 558 & 1.01 \\
12 & 0.08 & 2.69 & 2.31 & 0.21 & 530 & 0.95 \\
13 & 0.133 & 2.752 & 2.46 & 0.21 & 539 & 0.97
\end{tabular}


Таблица 4. Прочностные характеристики исследованных образцов

\begin{tabular}{c|l|c|c|c|c|c|l}
\hline $\begin{array}{c}\text { Номер } \\
\text { эксперимента }\end{array}$ & $\begin{array}{c}\text { ОСУНТ, } \\
\%\end{array}$ & $\begin{array}{c}\Delta u_{\mathrm{fs}}, \\
\mathrm{m} / \mathrm{s}\end{array}$ & $\begin{array}{c}u_{\mathrm{HEL}}, \\
\mathrm{m} / \mathrm{s}\end{array}$ & $\begin{array}{c}\sigma_{\mathrm{HEL}}, \\
\mathrm{GPa}\end{array}$ & $\begin{array}{c}\sigma_{\mathrm{sp}}, \\
\mathrm{GPa}\end{array}$ & $\begin{array}{c}h_{\mathrm{sp}}, \\
\mathrm{mm}\end{array}$ & $\begin{array}{c}\text { St.rate } \\
10^{5} \mathrm{~s}^{-1}\end{array}$ \\
\hline \multicolumn{7}{c}{ Метод I I } \\
\hline 1 & 0 & 235 & - & - & 0.37 & 0.57 & 0.93 \\
2 & 0 & 213 & 124 & 0.2 & 0.33 & 0.51 & 0.88 \\
3 & 0.001 & 234 & 180 & 0.29 & 0.36 & 0.42 & 1.3 \\
4 & 0.01 & 212 & 101 & 0.16 & 0.33 & 0.38 & 1.22 \\
5 & 0.1 & 192 & 144 & 0.23 & 0.31 & 0.42 & 1.25 \\
\hline \multicolumn{7}{|c}{ Метод II } \\
\hline 6 & 0 & 240 & 109 & 0.17 & 0.37 & 0.46 & 1.12 \\
7 & 0.004 & 218 & 109 & 0.17 & 0.34 & 0.46 & 1.06 \\
8 & 0.004 & 215 & 165 & 0.26 & 0.33 & 0.53 & 0.78 \\
9 & 0.01 & 179 & 96 & 0.15 & 0.32 & 0.49 & 0.82 \\
10 & 0.06 & 211 & 105 & 0.16 & 0.33 & 0.37 & 1.16 \\
11 & 0.08 & 223 & 153 & 0.24 & 0.35 & 0.37 & 1.47 \\
12 & 0.08 & 213 & 149 & 0.23 & 0.33 & 0.462 & 1.48 \\
13 & 0.133 & 215 & 173 & 0.28 & 0.33 & 0.37 & 1.25
\end{tabular}

$h_{\mathrm{sp}}=C_{l} \Delta t / 2$, где $\Delta t-$ время прохождения откольного импульса по откольной пластине, равное времени одной осцилляции скорости поверхности после откола. Под скоростью деформирования здесь понимается скорость расширения вещества в волне разрежения перед откольным разрушением, определяемая как

$$
\frac{\dot{V}}{V_{0}}=-\frac{\dot{u}_{\mathrm{fsr}}}{2 c_{b}},
$$

где $\dot{u}_{\mathrm{fsr}}-$ измеренная скорость спада скорости свободной поверхности образца в разгрузочной части импульса ударного сжатия перед отколом.

На рис. 4 представлены профили скорости свободной поверхности образцов ОЭК-І и ОЭК-II с различным содержанием ОСУНТ. Вариации максимальной скорости (максимального давления ударного сжатия), наблюдаемые в этих экспериментах, связаны как с разным затуханием волны сжатия на разных толщинах образцов, так и с разбросом скорости ударника, который в этих экспериментах мог доходить до $60 \mathrm{~m} / \mathrm{s}$.

В табл. 3 приведены характеристики исследуемых образцов, условия экспериментов и некоторые экспериментальные данные: процентное содержание ОСУНТ, измеренная продольная скорость звука $C_{l}$, толщина образца $h_{\text {обр}}$, толщина ударника $h_{\text {уд}}$, максимальная скорость поверхности $u_{\max }$ и соответствующее ей максимальное давление ударного сжатия. Продольная скорость звука $C_{l}$ измерялась методом „сквозного прозвучивания“ с помощью прибора УТ-93П. Максимальное давление в ударной волне рассчитывалось из выражения $P=\rho_{0} D u_{\mathrm{fs} \max } / 2[12]$, где $u_{\mathrm{fs} \max }-$ максимальная скорость на волновом профиле, $D$ - скорость ударной волны, определяемая из ударной адиабаты вещества, которая имеет вид $D=C_{0}+b u$, где коэффициент $C_{0}-$ величина, близкая по значению к объемной скорости звука материала при атмосферном давлении, $b-$ коэффициент, свой для каждого материала. Параметры ударной адибаты $C_{0}$ и $b$ определяются, как правило, по имеющимся экспериментальным данным. Поскольку содержание ОСУНТ в образцах очень мало, можно пренебречь влиянием нанотрубок на сжимаемость данного композита и использовать ударную адиабату отвержденной эпоксидной композиции. Ударная адиабата строилась по данным работы [14] и имеет вид $D=2.67+1.55 u$. Так как максимальное давление ударного сжатия в проведенных экспериментах было на уровне $1 \mathrm{GPa}$, то первый коэффициент в уравнении ударной адиабаты можно считать примерно равным объемной скорости звука $C_{0}$. С помощью данной адиабаты было рассчитано максимальное давление ударного сжатия образцов, а коэффициент $C_{0}=2.67 \mathrm{~km} / \mathrm{s}$ использовался как объемная скорость звука при расчете откольной прочности образцов.

В табл. 4 приведены прочностные характеристики образцов - откольная прочность $\sigma_{\mathrm{sp}}$, динамический предел упругости $\sigma_{\mathrm{HEL}}$, толщина откольной пластины $h_{\mathrm{sp}}$, скорость деформирования композита перед разрушением, рассчитанные по взятым из волновых профилей соответствующих значений скорости, также указанных в табл. 4 , где $\Delta u_{\mathrm{fs}}-$ спад скорости от максимума до первого минимума скорости, пропорциональный откольной прочности материала, $u_{\mathrm{HEL}}-$ амплитуда упругого предвестника, по которой определяется предел упругости материала (см. ниже). Для большей наглядности на рис. 5 представлена зависимость откольной прочности исследованных образцов от концентрации углеродных нанотрубок.

Видно, что даже при одинаковой концентрации нанотрубок наблюдается разброс значений откольной прочности до 10\%. Такие вариации разрушающих напряжений в одинаковых образцах, вероятно, связаны с наличием в их структуре агломератов ОСУНТ, выступающих

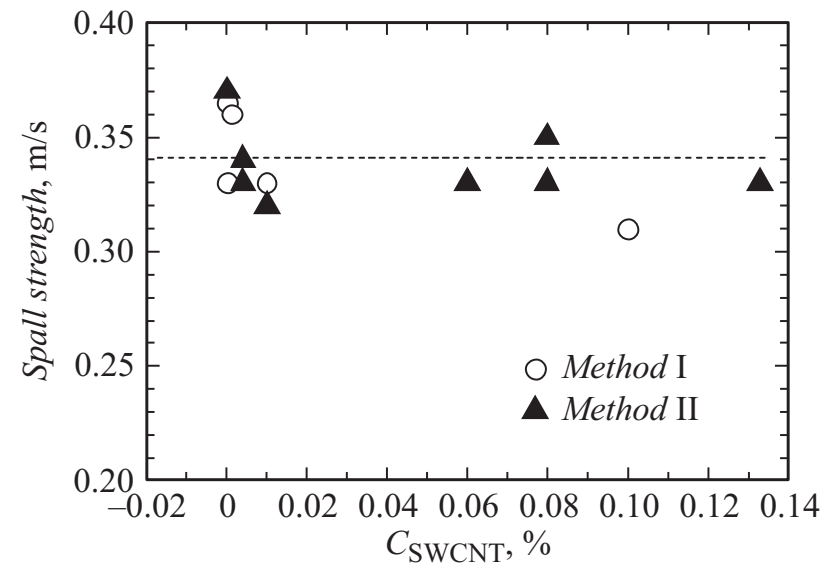

Рис. 5. Откольная прочность образцов ОЭК-І и ОЭК-ІІ с различным содержанием ОСУНТ. 


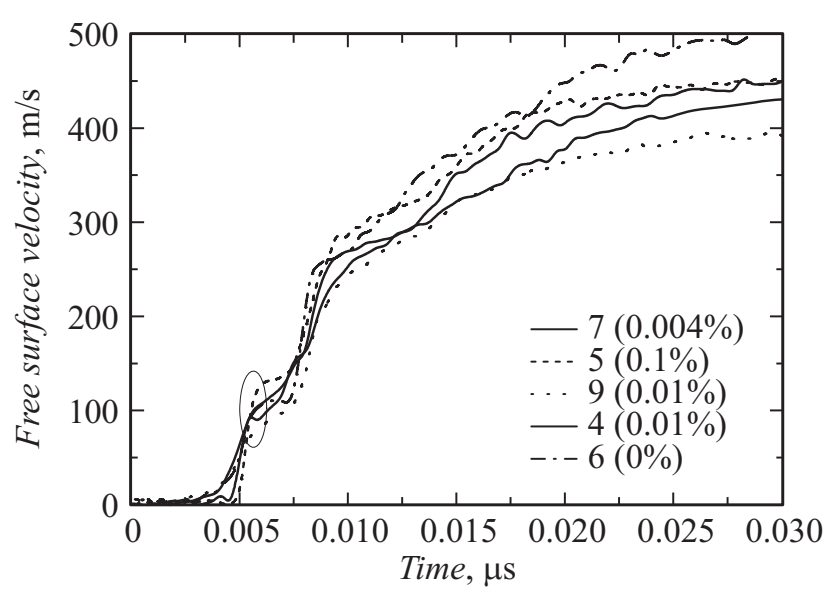

Рис. 6. Фронтальные части волновых профилей образцов ОЭК-І и ОЭК-ІІ с различным содержанием ОСУНТ. УП - область упругопластического перехода. Цифрами указаны номера образцов в соответствии с табл. 2, овалом указана область упругопластического перехода.

в роли концентраторов напряжений, имеющих неоднородное распределение по объему образца и являющихся очагами инициирования откольного разрушения. Тем не менее, принимая во внимание вышеизложенное соображение, видно, что изменение концентрации ОСУНТ в образцах практически не влияет на их сопротивление откольному разрушению, т. е. процесс его зарождения и развития происходит на грубых дефектах, а добавка в эпоксидную матрицу нанотрубок даже в виде их агломератов размером не более $150 \mathrm{~nm}$ не оказывает влияния на этот процесс в силу их малости. Это предположение подтверждают измерения толщины откольной пластины. Разброс этих данных от опыта к опыту при одинаковых условиях нагружения показывает, что откольная трещина зарождается на различных расстояниях от свободной поверхности, что возможно при неравномерном распределении „грубых“ концентраторов напряжений в образце.

Следует отметить еще одну особенность ударно-волнового деформирования исследованных образцов. При импульсных нагрузках динамический предел упругости, являющийся важной прочностной характеристикой любого материала, также определяется из анализа формоизменения волновых профилей в области упругопластического перехода. Вследствие разной сжимаемости веществ в области упругого и пластического деформирования исходная ударная волна теряет устойчивость и расщепляется на две волны сжатия - упругий предвестник, распространяющийся по веществу со скоростью, близкой к продольной скорости звука, и пластическую волну сжатия. Значение динамического предела упругости $\sigma_{\text {HEL }}$ (в английской транскриции HEL - Hugoniot Elastic Limit) рассчитывается по измеренной из волновых профилей амплитуде фронта упругого предвестника $u_{\mathrm{fs} H E L}$ как: $\sigma_{\mathrm{HEL}}=\rho_{0} C_{l} u_{\mathrm{fs} \mathrm{HEL}} / 2$. На рис. 6 представлены фронтальные части некоторых волновых профилей, зарегистрированных для образцов с различным содержанием ОСУНТ. Видно, что волновой фронт имеет структуру, состоящую из трех участков - резкий скачок параметров в первой волне сжатия до уровня 90-120 m/s, затем через 3-4 ns вторая волна сжатия примерно такой же амплитуды, после которой наблюдается плавное нарастание скорости до максимума. Аналогичную структуру имеют фронты всех волновых профилей, зарегистрированных в ударно-волновых экспериментах, кроме волнового профиля, зарегистрированного в эксперименте 1. В этом опыте максимальная скорость поверхности была примерно на 20-25\% выше средней величины максимальной скорости образцов в силу меньшего затухания волны сжатия из-за использования более толстого ударника. Как следствие, скорость пластической волны сжатия была выше и, по-видимому, равной или даже больше скорости упругой волны, что в свою очередь привело к формированию ударной волны сжатия без упругого предвестника и невозможности определения динамического предела упругости для этого образца.

При умеренных ударно-волновых нагрузках можно считать, что упругая волна сжатия распространяется с продольной скоростью звука, а пластическая волна с объемной. В этом предположении полученное из волновых профилей время расхождения волн соответствует рассчитанному по известной толщине образцов и измеренным скоростям звука. Таким образом, первая волна сжатия представляет собой упругую волну сжатия упругий предвестник, амплитуда которого пропорциональна динамическому пределу упругости образцов. Его значения, рассчитанные по указанному выше соотношению, приведены в табл. 4. Видимо, в силу структурной неоднородности образцов ОЭК величина динамического предела упругости также имеет достаточно большой разброс и практически не зависит от концентрации нанотрубок в эпоксидной матрице.

\section{Заключение}

Таким образом, в настоящей работе впервые проведены исследования, сочетающие изучение структуры, физико-механических свойств в статических и динамических условиях отвержденных эпоксидных композитов, содержащих малые и сверхмалые добавки одностенных углеродных нанотрубок. Полученные результаты свидетельствуют, что на структуру композитов оказывают влияние присутствующие в системе агломераты нанотрубок, размер которых зависит от способа приготовления ОЭК. Наличие указанных агломератов приводит к существенным абсолютным ошибкам измерений физико-механических параметров образцов как в статическом, так и в динамическом режимах измерений. При этом влияния на сами параметры одностенные нанотрубки в изученном интервале концентраций при обоих видах нагрузок не оказывают в отличие от случаев 
полиуретановых нанокомпозитов, содержащих сверхмалые добавки ОСУНТ при статических нагрузках [1]. Следует отметить, что сетка химических и физических связей в этих мягких полимерах далека от оптимальной, чего нельзя сказать о достаточно густой сетке в жестких отвержденных эпоксидных полимерах, использованных и в нашей работе. Откуда следует, что сверхмалые и малые добавки углеродных нанотрубок оказывают влияние на физико-механические свойства мягких полимеров, сетка связей которых, будь то химические или физические, далека от оптимальной. Это подтверждается и результатами работы [15], в которой продемонстрировано влияние малых добавок углеродных нанотрубок на физико-механические свойства отвержденных эпоксидов, полученных при намеренно выбранном недостаточном количестве отвердителя (мягкий полимер), и отсутствие такового влияния при эквимольном соотношении функциональных групп отвердителя и эпоксидной смолы. Таким образом, можно сделать вывод, что для существенного улучшения физико-механических свойств жестких полимеров с оптимальной сеткой необходимо использование достаточно высоких концентраций углеродных нанотрубок, что, однако, невыгодно как с технологической, так и с экономической точек зрения. В связи с этим необходимо продолжать исследования по поиску оптимальных нанонаполнителей, их эффективной функционализации, исследования синергетических эффектов при использовании различных наночастиц с целью существенного улучшения эксплуатационных свойств, важных в плане практического применения полиэпоксидов.

Работа выполнена по темам государственного задания, № гос. регистрации 01201361852 и 01201361856 и при финансовой поддержке Программ Президиума РАН № 1П и 11П и проекта Министерства образования и науки РФ № 14.578.21.0190.

\section{Список литературы}

[1] Эстрин Я.И., Бадамшина Э.Р., Гришук А.А., Кулагина Г.С., Лесничая В.А., Ольхов Ю.А., Рябенко А.Г., Сульянов С.Н. // Высокомолек. соед. А. 2012. Т. 54. № 4. C. $568-577$.

[2] Бадамшина Э.Р., Гафурова М.П., Эстрин Я.И. // Успехи химии. 2010. Т. 79. № 11. С. 945-979.

[3] Kausar A., Rafique I., Muhammad B. // Polymer-Plastics Technology and Engineering. 2016. Vol. 55. N 11. P. $1167-$ 1191.

[4] Jabeen S., Kausar A., Muhammad B., Gul S., Farooq M. // Polymer-Plastics Technology and Engineering. 2015. Vol. 54. N 13. P. 1379-1409.

[5] Garcia F., Soares B. // Polymer Testing. 2003. Vol. 22. N 1. P. 51-56.

[6] Hutchison J.L., Kiselev N.A., Krinichnaya E.P., Krestinin A.V., Morawsky A.P., Muradyan V.E., Zakharov D.N., Loutfy R.O., Obraztsova E.D., Terekhov S.V., Sloan J. // Carbon. 2001. Vol. 39. N 5. P. 761-770.
[7] Ryabenko A.G., Dorofeeva T.V., Zvereva G.I. // Carbon. 2004. Vol. 42. N 8-9. P. 1523-1535.

[8] Тарасов А.Е., Малков Г.В., Бубнова М.Л., Эстрин Я.И., Бадамшина Э.Р. // ЖПХ. 2015. Т. 88. Вып. 12. С. 1770 1775.

[9] Канель Г.И., Разоренов С.В., Уткин А.В., Фортов В.Е. Ударно-волновые явления в конденсированных средах. М.: Янус-К, 1996. 407 с.

[10] Barker L.M., Hollenbach R.E. // J. Appl. Phys. 1972. Vol. 43. N 11. P. 4669-4673.

[11] Kanel G.I. // Int J. Fract. 2010. Vol. 163. N 1. P. 173-191.

[12] Зельдович Я.Б., Райзер Ю.П. Физика ударных волн и высоко-температурных гидродинамических явлений. М.: Наука, 1966. 688 с.

[13] Antoun T., Seaman L., Curran D.R., Kanel G.I., Razorenov S.V., Utkin A.V. Spall Fracture. Springer, 2003. P. .404.

[14] M. van Thiel (Ed.). Compendium of shock wave data. Livermore: Lawrence Livermore Laboratory Report UCRL50108. 1977. P. 599.

[15] Ci L., Bai J. // Comp. Sci. Technol. 2006. Vol. 66. P. 599-603. 